\title{
Periarticular bone changes in rheumatoid arthritis: pathophysiological implications and clinical utility
}

\section{Steven R Goldring}

In recent decades there has been a dramatic change in the treatment approaches for management of rheumatoid arthritis (RA). The introduction of methotrexate and the subsequent development of the biological agents that target tumour necrosis factor (TNF) and/or immune cell activation pathways have dramatically improved patient outcomes. Nevertheless, as additional information becomes available from prospective studies of patients receiving these therapies, there is evidence that a significant number of individuals continue to experience progressive joint damage and functional impairment. ${ }^{1-6}$ Based on these observations, there is a need to develop validated assessment tools for identifying patients who are at risk for a poor prognosis and to target this population for more aggressive and/or specific therapies to prevent eventual joint damage. In this and a recent issue of the Annals of Rheumatic Diseases, two independent groups of investigators have utilised the techniques of bone mineral density (BMD) and radiographic analysis to assess bone loss in patients with early RA and to validate the changes in $\mathrm{BMD}$ as a predictor of subsequent radiographic evidence of focal marginal joint erosions. ${ }^{78}$

Both of the studies have exploited the evidence that the RA inflammatory process produces adverse effects on both local articular as well as systemic bone remodelling. ${ }^{9-13}$ The skeletal changes can be segregated into distinct patterns on the basis of anatomic site and distribution. These include focal marginal joint erosions (the radiographic hallmark of RA), subchondral bone erosions, periarticular osteoporosis and systemic osteoporosis. These skeletal changes are associated with net bone loss and in all instances are reflective of an imbalance in the activities of the cells that mediate bone resorption and formation.

Correspondence to: Steven R Goldring, Hospital for Special Surgery, 535 East 70th Street, New York, NY 10021, USA; goldrings@hss.edu
In the work by Hoff et al (see page 324), ${ }^{8}$ the investigators used digital $x$ ray radiogrammetry (DXR) to assess hand $\mathrm{BMD}$ in a population of patients with early RA. Conventional hand radiographs were used for both the radiographic scoring and for BMD measurement. The $\mathrm{BMD}$ assessment was performed on the cortical bone in the narrowest region of the second through the fourth metacarpals. ${ }^{14}$ The $\mathrm{BMD}$ results were then correlated with the development of radiographic joint damage over the subsequent 10 years employing the van Heijde modification of the Sharp method. They observed that patients with hand $\mathrm{BMD}$ loss at 1 year had significantly greater joint damage compared to patients without $\mathrm{BMD}$ loss. Importantly, they showed that the hand $\mathrm{BMD}$ loss was an independent predictor of subsequent joint damage and that the predictive power was comparable to the established biomarkers, anti-cyclic citrullinated peptide (CCP) and C-reactive protein (CRP). Their findings confirmed the results of previous longitudinal studies. ${ }^{9} 1516$

Multiple lines of evidence indicate that bone loss at both the metacarpal and joint margins reflect an imbalance in bone remodelling, and that the resorptive process is mediated via osteoclasts. These conclusions are based on histological observations of the bone resorption sites in periarticular bone and at the joint margins in patients with RA that confirm the presence of cells expressing definitive features of osteoclasts. ${ }^{17-19}$ More definitive evidence implicating osteoclasts in the pathogenesis of focal joint erosions comes from studies in knock-out mice with induced forms of inflammatory arthritis in which joint erosions fail to develop in the absence of osteoclasts. ${ }^{20-22}$ These results strongly implicate osteoclasts as the cell type responsible for the resorptive process at both sites. However, the observation that the loss of cortical bone density precedes the development of joint erosions, suggests that the imbalance in local bone remodelling at these sites may involve two distinct pathophysiological mechanisms. With respect to the pathogenesis of marginal erosions, the findings implicate a direct effect of the synovial pannus, which produces a plethora of potent osteoclast-inducing factors and has been shown to contain abundant osteoclast precursors. ${ }^{23-25}$ In addition, recent studies by Diarra et al ${ }^{26}$ demonstrate that the RA synovium is a source of dickkopf-1 (DKK-1), an inhibitor of bone formation that mediates its effects by inactivating the wingless (Wnt)-signalling pathway. The suppression of bone formation and increased resorptive activity likely account for the rapid rate of focal bone loss at the pannus-bone interface. ${ }^{26} 27$

In contrast, the loss of cortical bone at the metacarpal sites that are remote from the synovial and subchondral marrow inflammation implicate an alternate process that could reflect the adverse effects of reduced mechanical loading and relative joint immobilisation. These changes would be reflective of the property of bone to adapt its structural organisation in response to mechanical forces via remodelling according to Wolff's hypothesis that states that the distribution and material properties of bone are determined by the magnitude and direction of applied load. ${ }^{28}$ An alternate possibility is that cytokines released from the synovium and/or bone marrow could act via a local gradient effect or via systemic delivery to increase osteoclast-mediated bone loss at the metacarpal sites. This mechanism has been suggested to explain the adverse effects of synovial inflammation on generalised skeletal remodelling. ${ }^{101129}$ Of interest, in the Hoff study a subset of patients without hand BMD loss assessed by DXR experienced significant progressive marginal bone erosions. ${ }^{8}$ The disassociation between bone changes at the two sites provides additional indirect evidence suggesting that the pathogenic mechanisms responsible for the deregulated bone remodelling at the joint margins and periarticular location differs.

The studies by Guler-Yuksel et al provide further evidence linking changes in hand $\mathrm{BMD}$ measured by DXR with progression of erosive joint damage. As in the Hoff study, progression in bone erosions was independently associated with BMD loss. ${ }^{8}$ In addition to assessment of $\mathrm{BMD}$ and hand erosion scores, the authors also explored the relationship of skeletal changes at these sites with associated alterations in generalised skeletal BMD in the hip and spine measured by 
dual energy $x$ ray absorptiometry (DEXA). Furthermore, they evaluated the effects of treatment interventions on the bone parameters by conducting their skeletal site evaluation in a cohort of patients enrolled in the BeSt (for "Behandel Stratagieen", in English "treatment strategies") study. 31 Patients in the BeSt study were randomised to one of four treatment categories: sequential monotherapy, step up combination therapy, initial combination therapy with tapered high-dose prednisone, or combination therapy with infliximab.

The authors observed that there was $\mathrm{BMD}$ loss at all locations in all treatment groups, although combination therapy with prednisone and infliximab was associated with less hand BMD loss compared to the other groups. There were several additional observations of interest. Across the treatment groups there was greater $\mathrm{BMD}$ loss in the hands than the hip or spine, and the loss of BMD in the hands preceded the changes in hip and spine. Their findings confirm earlier observations ${ }^{32}{ }^{33}$ indicating a similar temporal relationship and suggest that differential pathogenic processes are involved in deregulated bone remodelling and bone loss systemically and in the hand.

The levels of multiple cytokines with osteoclast-inducing activity, including receptor activator of nuclear factor $(\mathrm{NF}) \kappa \beta$ ligand (RANKL) (an essential molecule that is required for osteoclast formation and activity) are elevated in the sera of patients with RA. The increased systemic bone loss in RA has been attributed to the adverse effects of RANKL and additional pro-osteoclastogenic cytokines that are released into the circulation from sites of synovial inflammation and act in a manner similar to endocrine hormones to modulate systemic bone remodelling. Studies by Geusens et $a^{34}$ support this speculation. They observed that the ratio of circulating RANKL and its inhibitor osteoprotegerin (OPG) predicted subsequent bone destruction in a cohort of patients with early RA. A similar endocrine-like mechanism also could contribute to impaired systemic bone formation. As discussed previously, Diarra et $a^{26}$ noted that patients with RA had elevated serum levels of DKK-1. Importantly, they observed that the levels of this potent inhibitor of bone formation correlated with disease activity. Both the periarticular bone and general skeleton would be subject to the influence of synovial-derived cytokines that could increase osteoclast-mediated bone resorption and suppress bone formation. As discussed earlier, the microenvironment in the metacarpal region likely is influenced by additional local factors that include reduced loading or adjacent inflammatory processes. These factors and influences would not be present throughout the skeletal. The differential pattern of bone loss in the hand and generalised skeleton need to be interpreted with some caution since, as the authors point out, both the sensitivity and bone tissue specificity of the two techniques differ.

Guler-Yuksel et al also observed that bisphosphonates protected only against generalised $\mathrm{BMD}$ loss in the hip and spine and had no significant effect on bone erosions or $\mathrm{BMD}$ in the hands. These findings confirm the observations of earlier studies indicating differential effects of bisphosphonates on focal erosions and systemic bone remodelling. ${ }^{35}$ In a recent study Jarrett et al demonstrated a beneficial effect of bisphosphonates in a series of patients with early RA; however, the effects were limited and large and repeated dosing was required. ${ }^{36}$ The high turnover of osteoclast generation and activity could partially explain the failure of bisphosphonates to effectively inhibit focal bone resorption. Alternatively, these agents may not concentrate adequately at the resorption sites, and more direct targeting of osteoclasts differentiation and activation may be necessary, as has been shown recently in preliminary trials with a humanised monoclonal antibody to RANKL in patients with early RA. ${ }^{37}$

The two above-mentioned manuscripts published in this journal provide further evidence of the association between periarticular bone loss and focal joint erosions. The pattern of bone loss provides insights into the underlying pathogenic mechanisms responsible for the deregulated bone remodelling and importantly suggests the potential utility of this diagnostic approach for predicting the natural history of RA joint damage and implementation of treatment approaches.

Funding: This work was supported in part by National Institute of Health Grant NIAMS R01 AR45472 and American College of Rheumatology Research and Education Foundation (ACR-REF) Within Our Reach: Finding a Cure for Rheumatoid Arthritis.

\section{Competing interests: None.}

Accepted 16 November 2008

Ann Rheum Dis 2009;68:297-299.

doi:10.1136/ard.2008.099408

\section{REFERENCES}

1. Genovese MC, Becker JC, Schiff M, Luggen M, Sherrer Y, Kremer J, et al. Abatacept for rheumatoid arthritis refractory to tumor necrosis factor alpha inhibition. N Engl J Med 2005;353:1114-23.
2. Klareskog L, van der Heijde D, de Jager JP, Gough A, Kalden J, Malaise M, et al. Therapeutic effect of the combination of etanercept and methotrexate compared with each treatment alone in patients with rheumatoid arthritis: double-blind randomised controlled trial. Lancet 2004;363:675-81.

3. Landewe R, van der Heijde D, Klareskog $L$, van Vollenhoven R, Fatenejad S. Disconnect between inflammation and joint destruction after treatment with etanercept plus methotrexate: results from the trial of etanercept and methotrexate with radiographic and patient outcomes. Arthritis Rheum 2006;54:3119-25.

4. Smolen JS, Han C, Bala M, Han C, Bala M, Maini $\mathrm{RN}$, et al. Evidence of radiographic benefit of treatment with infliximab plus methotrexate in rheumatoid arthritis patients who had no clinical improvement: a detailed subanalysis of data from the anti-tumor necrosis factor trial in rheumatoid arthritis with concomitant therapy study. Arthritis Rheum 2005; 52:1020-30.

5. van der Heijde D, Landewe R, Klareskog $L$, Rodriguez-Valverde V, Settas L, Pedersen R, et al. Presentation and analysis of data on radiographic outcome in clinical trials: experience from the TEMPO study. Arthritis Rheum 2005:52:49-60.

6. Wick MC, Lindblad S, Klareskog L, Van Vollenhoven RF. Relationship between inflammation and joint destruction in early rheumatoid arthritis: a mathematical description. Ann Rheum Dis 2004;63:848-52.

7. Guler-Yuksel M, Allaart CF, Goekoop-Ruiterman YPM, de Vries-Bouwstra JK, van Groenendael JHLM, Mallee $\mathrm{C}$, et al. Changes in hand and generalized bone mineral density in patients with recent-onset rheumatoid arthritis. Ann Rheum Dis 2008;67:823-8.

8. Hoff M, Haugeberg G, Odegard S, Syversen S, Landewe R, van der Heijde D, et al. Cortical hand bone loss after 1-year in early rheumatoid arthritis predicts radiographic hand joint damage at 5 - and 10 year follow-up. Ann Rheum Dis 2009:68:324-9.

9. Deodhar AA, Brabyn J, Pande I, Scott DL, Woolf AD. Hand bone densitometry in rheumatoid arthritis, a five year longitudinal study: an outcome measure and a prognostic marker. Ann Rheum Dis 2003;62:767-70.

10. Goldring SR, Gravallese EM. Mechanisms of bone loss in inflammatory arthritis: diagnosis and therapeutic implications. Arthritis Research 2000:2:33-7.

11. Haugeberg G, Orstavik RE, Kvien TK. Effects of rheumatoid arthritis on bone. Curr Opin Rheumatol 2003;15:469-75.

12. Orstavik RE, Haugeberg G, Mowinckel P, Holseth A, Uhlig T, Falch JA, et al. Vertebral deformities in rheumatoid arthritis: a comparison with populationbased controls. Arch Intern Med 2004;164:420-5.

13. Orstavik RE, Haugeberg G, Uhlig T, Mowinckel P, Falch JA, Halse Jl, et al. Incidence of vertebral deformities in 255 female rheumatoid arthritis patients measured by morphometric $\mathrm{X}$-ray absorptiometry. Osteoporos Int 2005;16:35-42.

14. Rosholm A, Hyldstrup L, Backsgaard L, Grunkin M, Thodberg HH. Estimation of bone mineral density by digital X-ray radiogrammetry: theoretical background and clinical testing. Osteoporos Int 2001;12:961-9.

15. Haugeberg G, Green MJ, Conaghan PG, Ouinn M, Wakefield R, PRoudman SM, et al. Hand bone densitometry: a more sensitive standard for the assessment of early bone damage in rheumatoid arthritis. Ann Rheum Dis 2007;66:1513-7.

16. Stewart A, Mackenzie LM, Black AJ, Reid DM. Predicting erosive disease in rheumatoid arthritis. A longitudinal study of changes in bone density using digital X-ray radiogrammetry: a pilot study. Rheumatology (Oxford) 2004:43:1561-4.

17. Bromley M, Woolley DE. Histopathology of the rheumatoid lesion; identification of cell types at sites of cartilage erosion. Arthritis Rheum 1984;27:857-63.

18. Gravallese EM, Harada Y, Wang JT, Gorn AH, Thornhill TS, Goldring SR. Identification of cell types responsible for bone resorption in rheumatoid arthritis and juvenile rheumatoid arthritis. Am J Pathol 1998;152:943-51. 
19. Shimizu S, Shiozawa S, Shiozawa K, Imura S, Fujita T. Quantitative histologic studies on the pathogenesis of periarticular osteoporosis in rheumatoid arthritis. Arthritis Rheum 1985:28:25-31.

20. Li P, Schwarz EM, O’Keefe RJ, Ma L, Boyce BF, Xing L. RANK signaling is not required for TNF $\alpha$-mediated increase in CD11(hi) osteoclast precursors but is essential for mature osteoclast formation in TNF $\alpha$ mediated inflammatory arthritis. J Bone Miner Res 2004; 19:207-13.

21. Pettit AR, Ji H, von Stechow D, Muller R, Goldring SR, Choi $Y$, et al. TRANCE/RANKL knockout mice are protected from bone erosion in a serum transfer model of arthritis. Am J Pathol 2001;159:1689-99.

22. Redlich K, Hayer S, Ricci R, David, JP, TohidastAkrad M, Kollias G, et al. Osteoclasts are essential for TNF-alpha-mediated joint destruction. J Clin Invest 2002:110:1419-27.

23. Goldring SR. Pathogenesis of bone erosions in rheumatoid arthritis. Curr Opin Rheumatol 2002;14:406-10.

24. Goldring SR, Gravallese EM. Pathogenesis of bone erosions in rheumatoid arthritis. Curr Opin Rheumatol 2000:12:195-9.
25. Herman S, Kronke G, Schett G. Molecular mechanisms of inflammatory bone damage: emerging targets for therapy. Trends Mol Med 2008;14:245-53.

26. Diarra D, Stolina M, Polzer K, Zwerina J, Ominsky MS, Dwyer D, et al. Dickkopf-1 is a master regulator of joint remodeling. Nat Med 2007;13:156-63.

27. Goldring SR, Goldring MB. Eating bone or adding it: the Wnt pathway decides. Nat Med 2007;13:133-4.

28. Frost HM. Bone's mechanostat: a 2003 update. Anat Rec A Discov Mol Cell Evol Biol 2003;275:1081-101.

29. Walsh NC, Crotti TN, Goldring SR, Gravallese EM. Rheumatic diseases: the effects of inflammation on bone. Immunol Rev 2005;208:228-51.

30. Goekoop-Ruiterman YP, de Vries-Bouwstra JK, Allaart CF, van Zeben D, Kersten PJ, Hazes JM, et al. Comparison of treatment strategies in early rheumatoid arthritis: a randomized trial. Ann Intern Med 2007:146:406-15.

31. Goekoop-Ruiterman YP, de Vries-Bouwstra JK, Allaart CF, van Zeben D, Kersten PJ, Hazes JM, et al. Clinical and radiographic outcomes of four different treatment strategies in patients with early rheumatoid arthritis (the BeSt study): a randomized, controlled trial. Arthritis Rheum 2005;52:3381-90.
32. Deodhar AA, Woolf AD. Bone mass measurement and bone metabolism in rheumatoid arthritis: a review. Br J Rheumatol 1996;35:309-22.

33. Devlin J, Lilley J, Gough A, Huissoon A, Holder R, Reece $\mathrm{R}$, et al. Clinical associations of dual-energy $\mathrm{X}$-ray absorptiometry measurement of hand bone mass in rheumatoid arthritis. Br J Rheumatol 1996:35:1256-62.

34. Geusens PP, Landewe RB, Garnero P, Chen D, Dunstan $\mathrm{CR}$, Lems WF, etal. The ratio of circulating osteoprotegerin to RANKL in early rheumatoid arthritis predicts later joint destruction. Arthritis Rheum 2006;54:1772-7.

35. Goldring SR, Gravallese EM. Bisphosphonates: environmental protection for the joint? Arthritis Rheum 2004;50:2044-7

36. Jarrett SJ, Conaghan PG, Sloan VS, Papanastasiou $\mathrm{P}$, Ortmann CE, O'Connor PJ, et al. Preliminary evidence for a structural benefit of the new bisphosphonate zoledronic acid in early rheumatoid arthritis. Arthritis Rheum 2006;54:1410-4.

37. van der Heijde D, Cohen S, Sharp JT, Ory P, Zhou L, Tsuji W, et al. Denosumab inhibits RANKL, reducing progression of the total Sharp score and bone erosions in patients with rehumatoid arthritis: 12month X-ray results. Arhtritis Rheum 2007:56:S299.

\section{Drug and Therapeutics Bulletin (DTB)}

\section{Your key source of unbiased, independent advice}

For over 45 years DTB has been an independent, indispensable part of evidence-based clinical practice. DTB offers healthcare professionals detailed assessment of, and practical advice on, individual medicines and other treatments, groups of treatment and the overall management of disease.

DTB is now also available online at http://dtb.bmj.com:

- browse or search all DTB content from the latest issue back to 1994

- email alerting, sophisticated searching, RSS feeds and full text links from cited references

- interactive services such as My Folders for quick access to articles that you have viewed previously and My Searches to save and re-use useful searches

- comment online on any DTB article

To subscribe, or for further information, please visit http://dtb.bmj.com 


\section{Corrections}

doi:10.1136/ard.2007.085050.corr1

An article published in September 2008 (A Martínez, J Varadé, J R Lamas, et al. GDF5 Polymorphism associated with osteoarthritis: risk for rheumatoid arthritis. Ann Rheum Dis 2008;67:1352-3) did not sufficiently reference the ideas published in the following article: Reines BP. Is rheumatoid arthritis premature osteoarthritis with fetal-like healing? Autoimmun Rev 2004;3:305-11. Reines's model provided a great deal of the impetus for searching for a GDF5 polymorphism associated with rheumatoid arthritis. The authors apologise for this.

An author name was incorrect in the an article published in February 2009 (G Moroni, A Radice, $\mathrm{G}$ Giammarresi, et al. Are laboratory tests useful for monitoring the activity of lupus nephritis? A 6-year prospective study in a cohort of 228 patients with lupus nephritis. Ann Rheum Dis 2009;68: 234-7). The seventh author's name should have been given as M Li Vecchi, not M L Vecchi as given in the article.

Ann Rheum Dis 2009;68:1080. doi:10.1136/ard.2008.094508.corr1

A reference was incorrect in an editorial published in March 2009 (Goldring SR. Periarticular bone changes in rheumatoid arthritis: pathophysiological implications and clinical utility. Ann Rheum Dis 2009;68:297-9). Reference 7 should read: Güler-Yüksel M, Allaart CF, Goekoop-Ruiterman YPM, de Vries-Bouwstra JK, van Groenendael JHLM, Mallée C, et al. Changes in hand and generalised bone mineral density in patients with recent-onset rheumatoid arthritis. Ann Rheum Dis 2009; 68:330-6.

Ann Rheum Dis 2009;68:1080. doi:10.1136/ard.2008.099408.corr1 